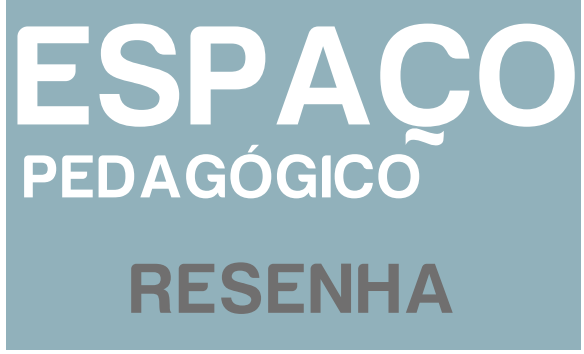




\title{
Da universidade à commoditycidade: ou de como e quando, se a educação/ formação é sacrificada no altar do mercado, o futuro da universidade se situaria em algum lugar do passado
}

From the university to the commodity: or how and when, if education/training is sacrificed on the market altar, the university's future would be somewhere in the past

De la universidad a la comoditycidad: o cómo y cuándo, si la educación/formación és sacrificada en el altar del mercado, el futuro de la universidad estaría en algún lugar del pasado

\author{
Maria de Lourdes Pinto de Almeida* \\ Silmara Terezinha Freitas ${ }^{* *}$ \\ Diego Palmeira Rodrigues ${ }^{* * *}$
}

Refletir sobre a universidade é muito importante para compreendermos a dinâmica histórica da Educação Superior e o contexto de influências que interferem na autonomia da universidade e que a colocam como mais um instrumento a serviço do mercado. É nesta perspectiva que foram elaboradas as reflexões contidas na obra "Da universidade à commoditycidade: ou de como e quando, se a educação/ formação é sacrificada no altar do mercado, o futuro da universidade se situaria em algum lugar do passado", publicada pela editora Mercado de Letras (Brasil) em setembro de 2017.

Escrito em coautoria pelos Professores Lucídio Bianchetti e Valdemar Sguissardi, o livro tem o objetivo de apresentar, por meio de 124 páginas, o histórico da universidade ocidental desde sua origem até o momento atual. Para tanto, os

Recebido em 27/04/2019 - Aprovado em 04/09/2019

http://dx.doi.org/10.5335/rep.v27i1.10588

Doutora em Educação pela Universidade Estadual de Campinas (Unicamp, Brasil). Professora Titular da Universidade do Oeste de Santa Catarina (Unoesc, Brasil). ORCID https://orcid.org/0000-0001-8515-2908. E-mail: malu04@gmail.com

Especialista em Coordenação Pedagógica pela Universidade Federal de Santa Catarina (Ufsc, Brasil). Mestre em Educação pela Universidade do Oeste de Santa Catarina (Unoesc, Brasil). ORCID https://orcid.org/0000-0003-1657-4781. E-mail: silmara.fisica@gmail.com

*** Doutorando em Educação pela Universidade do Oeste de Santa Catarina (Unoesc, Brasil). ORCID https://orcid. org/0000-0002-2431-654X.E-mail: diegopalmeirarodrigues@gmail.com 
capítulos tecem discussões construídas sob um olhar crítico quanto ao processo de intervenção sobre o qual sempre passou a universidade.

Com uma redação dotada de coerência argumentativa, possibilita perceber um encadeamento entre os três capítulos que compõem a obra e são assim intitulados: "Universidade, Tutelas e Políticas Educacionais: Da instituição medieval à moderna. Alguns antecedentes da situação atual"; "Brasil: De Instituições de Ensino Superior Tuteladas - Passando por experiências fundantes - à regulação"; e “... À Commoditycidade”. Antecedendo os capítulos, constam o prefácio intitulado "Da universidade à commmoditycidade: mudança ou metamorfose na Educação Superior?", escrito por Almerindo Janela Afonso, e uma breve introdução. Nas páginas finais são expostas as Referências dos autores citados ao longo de todo o texto e ainda, em Sobre os autores é apresentada uma breve descrição do currículo e o e-mail de contato dos autores Bianchetti e Sguissardi.

O livro fornece uma leitura crítica do contexto em que a Universidade Contemporânea está envolta, a partir de uma análise que se inicia por uma tênue linha do tempo da história da criação das universidades brasileiras, apresentando os dilemas sofridos e os desafios com os quais, atualmente, elas se enfrentam no campo da investigação, reflexão e formação. Já no prefácio da obra, os leitores são brindados com uma excelente descrição da magnitude do livro realizada por Almerindo Janela Afonso, o qual enfatiza que os autores apresentam de maneira clara e ao mesmo tempo crítica, que com o passar do tempo as Instituições de Ensino Superior (IES) foram sofrendo rupturas do ethos da universidade em função dos interesses do capitalismo, transformando-se numa organização subordinada às lógicas mercantis.

$\mathrm{Na}$ introdução os autores Bianchetti e Sguissardi apresentam quais são os contextos que delineiam a obra, situando o leitor no espaço e no tempo histórico no qual as universidades brasileiras foram criadas e como essas foram sendo tuteladas e perdendo a autonomia até chegar ao extremo de regulação heterônoma. Nesse sentido, apresentam também o Parecer 977/65, que institui os programas de pós-graduação stricto sensu, o qual, no Capítulo II, é discutido detalhadamente como o marco criado com o intuito de renovar, reconstruir, qualificar e transformar a instituição universitária, pois é neste âmbito que os autores buscam demonstrar o contexto no qual a educação superior pública se estagnou, abrindo caminho para a expansão das instituições privadas, as quais se tornaram, nas palavras dos autores, "protagonistas" do efetivo processo de mercadorização da educação superior. 
Com essa abordagem, os autores explicam o significado do termo que define o título da obra: commoditycidade - expressão essa que é usada de maneira heurística para explicar o processo de transformação, tanto da definição, quanto do funcionamento da universidade e da própria educação superior, no sentido de a educação ser tratada como mercadoria.

No Capítulo I, Universidade, Tutelas e Políticas Educacionais: Da instituição medieval à moderna. Alguns antecedentes da situação atual, é apresentada uma linha do tempo que explicita a condição da universidade tutelada, no início, pelo domínio da Igreja (Idade Média - Europa), já no século XVI, pela burguesia na fase comercial do capitalismo, momento em que a estrutura e as funções da universidade passaram por transformações e que se agregou à educação o termo "laica". Nessa parte do texto, os autores destacam que na condição de universidade tutelada, as transformações ocorridas desde a criação das universidades até o século XIX foram mínimas no que tange aos objetivos, estrutura e modo de organização e funcionamento das instituições (p. 23).

Seguindo a linha cronológica, de acordo com os autores, no século XIX emerge a questão social em que são criadas as universidades cuja identidade passam a deslocar-se do lugar, não apenas geograficamente, em que algumas continuam sendo tuteladas, enquanto outras são direcionadas a fins como pesquisa e prestação de serviços com o desafio de gestões ou regulações menos tuteladoras (p. 25).

Na parte final do capítulo, Bianchetti e Sguissardi enfocam um pouco da história da universidade/educação superior no Brasil. A abordagem começa pelo século XVIII em que a influência em termos de educação superior é napoleônica, quando o Rei D. João VI, ao chegar no Brasil, autoriza o funcionamento das escolas superiores com características de faculdades para atender as necessidades da coroa portuguesa, ofertando curso de Direito, Medicina, Engenharia Naval, Mineralurgia. Contudo, após apresentação de um breve relato da instituição das universidades brasileiras, os autores sinalizam para a importância em se perceber que com o passar do tempo as exigências da divisão técnica e social do trabalho foram impondo a maneira como a universidade foi sendo organizada e funcionando na direção tanto de especializações, terminalidades, quanto nas áreas de saber insulares, voltadas para atender as demandas do mercado, no sentido de formar especialistas (p. 28).

$\mathrm{O}$ fechamento da primeira parte do livro situa-se na abordagem referente ao século XIX, momento em que pelas inúmeras transformações na forma de organização e funcionamento das universidades, foram estabelecidos os modelos que passaram a predominar até os dias atuais, ou seja, foi a partir de então que se ma- 
terializou o tripé da universidade: ensino, pesquisa e extensão, mas com diferentes pesos e medidas, administradas e geridas como organizações e desta forma cada vez mais se distanciando como instituição educativa em sua essência.

O Capítulo II intitulado Brasil: De Instituições de Ensino Superior Tuteladas Passando por experiências fundantes - à regulação, conecta a história da educação superior no Brasil, a qual se iniciou em 1808, com os aspectos da evolução da sociedade, que guiada pelo capitalismo, foi caracterizando a educação superior num contexto de tutela e pragmatismo utilitarista dos cursos superiores. Os autores novamente seguindo uma linha do tempo, vão expondo fatos pontuais referente à criação de cursos, iniciando pelo período imperial ${ }^{1}$ até a passagem da primeira para a segunda década do século XX onde surgem as universidades privadas (Manaus 1909, São Paulo - 1911 e Curitiba - 1912).

Tecendo considerações sobre a "identidade" do ensino superior, na sequência do capítulo, são apresentadas considerações a respeito de como as relações entre a universidade e a sociedade foram caracterizando o modelo contemporâneo de universidade a partir de três experiências/modelos de universidade/educação superior: a Universidade de São Paulo (USP), a Universidade do Distrito Federal (UDF) e a Universidade de Brasília (UnB). Para os autores, essas três instituições foram criadas com objetivos de resgatar o sentido original de universidade e alimentar o pensamento crítico e reflexivo, destacam ainda que nos documentos dessas instituições está presente a preocupação com a formação de professores em todos os níveis.

Nesse sentido, o seguimento do capítulo expõe os fatos que originaram a criação e implantação formal de um modelo de pós-graduação stricto sensu, tendo como marco inicial o parecer 977/65, o foco da implementação estava voltado à renovação ou reconstrução da universidade brasileira a partir do ideário de melhoria da/na formação de professores. Contudo, os autores alertam para o fato de que tanto o nome quanto o sistema da pós-graduação têm sua origem na estrutura das universidades norte-americanas e que isso está explícito no referido parecer. Assim, finalizando o capítulo, são apresentados argumentos e detalhes que nos levam a entender como foi constituída a pós-graduação stricto sensu no Brasil, como por exemplo, a questão referente à sua regulamentação e às implicações na carreira docente, enfocando a necessidade da regulação, do controle em relação à abertura dos cursos (p.72).

No Capítulo III, À Commoditycidade, são expostos alguns fatos e argumentos que esclarecem a maneira de como a perspectiva de mercado está presidindo o pro- 
cesso de ampliação do número de Instituições, sejam novas ou resultados de processos de fusões. Nesse sentido, o termo usado como título da obra "commoditycidade" representa essa nova especificidade das Instituições de Educação Superior, com características de empresas mercantis que buscam ampliação numérica de alunos-clientes (p.76).

Pelo detour apresentado pela linha do tempo, os autores reúnem alguns elementos da história da educação superior/universidade, relacionando o passado mais distante com o presente, com o fito de prospectar o cenário para os próximos anos, caso se mantenha essa tendência que têm se mostrado hegemônica, a mercantilização da educação. De maneira reflexiva frente a esse possível cenário para a educação superior, indagam: Quais são as indicações reveladoras do futuro da formação dos jovens universitários, no plano imediato, mediato e de longo prazo, a prevalecer a tendência que vem se impondo como hegemônica no atual processo de expansão da educação superior? (p. 80).

A fim de ilustrar a expansão da educação superior, é apresentado um caso como exemplo, o de Santa Catarina que mesmo com o Sistema Acafe (Associação Catarinense das Fundações Estaduais) também sucumbiu à expansão de instituições e organizações privadas-mercantis. Ainda são apresentados fatos pontuais que representam o processo de mercantilização da educação: a ida de "empresas de educação" à Bolsa de Valores, ou seja, a abertura de capital das empresas educacionais onde se formam monopólios e oligopólios a partir da aquisição e incorporação entre algumas empresas do setor educacional pela compra e venda de ações na Bolsa de Valores, de um produto chamado "educação/ensino", transformando esse produto em mercadoria/commodity, momento no qual, bem enfatizam os autores, a condição da universidade, da educação superior e dos alunos chega ao extremo representado pela "mercadoria/ensino" que se negocia na bolsa de valores, uma estratégia mercantil que segue as lógicas do capital (p. 95).

Com a subseção do capítulo Oligopolização da educação superior, os autores trazem à discussão um pouco da história da constituição da maior empresa de educação superior do planeta - a Kroton - a partir da exposição de dados e tabelas com informações a respeito do número de matrículas em instituições educacionais com fins lucrativos vinculadas a esse grupo, os autores enfatizam ainda mais a questão de que a tendência hegemônica firmada para a universidade contemporânea é voltada aos interesses imediatos de empresas, descaracterizando a quase milenar missão universitas voltada à formação cultural e humanística. 
Na Conclusão da obra Bianchetti e Sguissardi apresentam uma crítica aos "ataques" sofridos pela universidade no decorrer da história que se materializam na forma da educação tratada como mercadoria vendável, do aluno como cliente/ comprador e também da formação mínima e simplesmente utilitária.

O livro "Da universidade à commoditycidade: ou de como e quando, se a educação/formação é sacrificada no altar do mercado, o futuro da universidade se situaria em algum lugar do passado" configura-se como uma importante contribuição para as discussões sobre os caminhos percorridos pela Universidade e o contexto de influencias no seu entorno. É uma importante obra de referência para os estudos sobre Universidade e ensino superior e, dessa forma, é uma leitura recomendada a todos interessados em conhecer o percurso histórico da Universidade e as influências por ela sofrida. É uma obra especialmente indicada aos que pesquisam na área de políticas públicas educacionais.

\section{Nota}

1 Neste período foram criadas as Faculdades de Direito devido à necessidade de formação humanística- jurídica para realizar as tarefas de administração do país e das províncias (p. 36).

\section{Referência}

BIANCHETTI, Lucídio; SGUISSARDI, Valdemar. Da universidade à commoditycidade: ou de como e quando, se a educação/formação é sacrificada no altar do mercado, o futuro da universidade se situaria em algum lugar do passado. Campinas, SP: Mercado das Letras, 2017. 